\title{
Methods of Measuring Rheological Properties of Interfacial Layers (Experimental Methods of 2D Rheology)
}

\author{
S. R. Derkach ${ }^{a}$, J. Krägel ${ }^{b}$, and R. Miller ${ }^{b}$ \\ ${ }^{a}$ Murmansk State Technical University, Sportivnaya ul. 13, Murmansk, 183010 Russia \\ ${ }^{b}$ Max-Plank Institute of Colloids and Interfaces, Potsdam/Golm, D 14476 Germany \\ Received February 13, 2008
}

\begin{abstract}
Current methods of studying the rheological properties of interfacial layers at the interfaces of fluids are reviewed. This area of research includes two-dimensional 2D rheology. Regardless of the similarities between the parameters of rheological properties of two-dimensional and bulk (three-dimensional) systems, when measuring surface properties, it is necessary to reformulate the main experimental methods to allow for the different dimensions of surface and bulk characteristics of material. Parameters of shear and dilational (measured upon expansion-compression) properties of interfacial layers are distinguished, and the latter are considered to be independent parameters of a system. The most attention was given to the rotational methods of measuring shear viscosity and the components of the complex 2D elastic modulus, as well as to measuring surface tension upon harmonic changes of the bubble (droplet) surface area, which allows characteristics of the dilational behavior of thin liquid films to be determined. Both groups of methods are widely used in laboratory practice and realized in the form of a number of original and commercial instruments. Dilational measurements of interfacial layers can also be performed with oscillations of a movable barrier on a Langmuir trough. In addition, methods based on the propagation of capillary waves across the surface of a liquid, as well as rarer methods of capillary flow in thin channels forced by either a surface tension gradient or the motion of the interface, are considered.
\end{abstract}

DOI: $10.1134 / \mathrm{S} 1061933 \mathrm{X} 09010013$

\section{INTRODUCTION}

The idea that surface properties of a liquid are essentially different from those of its bulk seems to be quite evident. Many methods for measuring specific properties of liquid surfaces have been accepted standard and are used in everyday laboratory practice. Above all, these include methods for measuring surface tension as the most important property of a liquid surface, which are performed using many procedures based on equilibrium thermodynamics multicomponent liquid systems [1].

At the same time, another complex of the characteristics of surface properties of liquid, which are related to mechanical behavior, is of great theoretical and applied interest; these are the properties of an interface associated with the term two-dimensional or $2 \mathrm{D}$ rheology. An excellent theoretical introduction to 2D rheology is the chapter Basics of Interface Rheology in a monograph written by $\operatorname{Krotov}^{1}$ [2].

The measurements of rheological surface characteristics are important for studying versatile systems, ranging from pure liquids to colloidal systems and polymer solutions. However, it should be emphasized that, in the majority of cases, the objects for investigation in 2D rheology are interfacial layers of surfactants, including proteins and surface-active polymers. Interfacial layers are either organized spontaneously at liquid interfaces due to adsorption of surfactants from solution or formed mechanically by depositing insoluble surfactant layers on the surface of a liquid phase. The thickness of these interfacial layers of surfactants does not exceed a few nanometers $[1,4]$, which allows these layers to be referred to as two-dimensional systems.

The aim of measuring the rheological characteristics of interfacial layers, as well as any measurements of quantitative characteristics of a material, is their comparison with the composition and internal structure of this material in order to eventually predetermine the choice and optimization of its composition for some applications.

This review is devoted to the consistent description of known experimental methods in 2D rheology, a part of which is realized in form of commercially manufac-

\footnotetext{
${ }^{1}$ In memory of the late Professor V. V. Krotov (1931-2007), the Head of the Laboratory of Surface Phenomena, St. Petersburg State University. He was one of the pioneers of 2D rheology and the author of numerous publications related both to the theoretical basis and experimental results of this field of research. In the early years of this laboratory, he developed a unique setup for studying the equilibrium elasticity of free liquid films, which made it possible for the first time to quantitatively verify the existence of the Gibbs elasticity of films. He also proposed original procedures for studying foams and capillary jets. In 1999, his monograph (coauthored by Academician A. I. Rusanov) entitled "Physicochemical Hydrodynamics of Capillary Systems" [3] was published.
} 
tured devices, while the other part, which is possibly more exotic, is most likely of theoretical interest, although their use in developing commercial devices cannot be excluded.

We will not dwell upon the results of measurements and their relation to the structure and composition of studied systems because this problem seems to us to be independent, ample, and important.

\section{DEFINITIONS}

Definitions of parameters subjected to measurements in 2D rheology are related to the analogous notions and definitions used in classical rheology [5]. However, notions and definitions were reformulated because we deal here with surface (two-dimensional) rather than bulk (three-dimensional) properties [2, 3].

Thus, fundamental characteristics in our discussion are stress $\tau$, which is understood as the force referred to a unit length (albeit not to unit surface area as in continuum mechanics), and strain $\gamma$, which, as usual, represents the relative change in the distance between two infinitely close point in the continuum.

Then, surface shear viscosity $\eta_{\mathrm{s}}$ is expressed, in full keeping with the classical Newton law, as,

$$
\eta_{\mathrm{s}}=\frac{\tau}{\dot{\gamma}}
$$

where $\dot{\gamma}$ is the strain rate.

The dimension of the value of surface (or 2D) viscosity has the form of $[(\mathrm{N} \mathrm{s}) / \mathrm{m}]$, not $\left[(\mathrm{N} \mathrm{s}) / \mathrm{m}^{2}\right]$ as in the rheology of bulk materials.

The notion of the existence of surface viscosity was probably introduced into science for the first time by Plateau [6] and the fundamental term of surface elasticity was formulated by Gibbs [7].

In addition to shear viscosity $\eta_{s}$, a substantial significance in the theory of surface properties belongs to socalled surface dilational viscosity $\eta_{\mathrm{d}}$, which is analogous to longitudinal viscosity (the viscosity measured in expansion, but not in shear) in the rheology of bulk media. However, as a rule, this parameter in $2 \mathrm{D}$ rheology is considered to include the deformation of a twodimensional surface rather than a uniaxial stretching deformation. We should additionally mention that, in the theory of viscous Newtonian liquids, there is an rigorous correlation between shear viscosity $\eta$ and longitudinal (so-called Trouton) viscosity $\lambda$, i.e., $\lambda=3 \eta[5]$, which is absent in the theory of surface flow. The $\eta_{\mathrm{s}}$ and $\eta_{\mathrm{d}}$ parameters are considered to be independent rheological surface characteristics that is probably not entirely correct.

Regimes of periodic deformation, which in rheology are usually called dynamic regimes, are used in the study of viscoelastic interfacial layers in the region of linear viscoelasticity (as it is done in the study of threedimensional bodies). Shear deformation applied to a surface changes with time $t$ according to harmonic law

$$
\gamma(t)=\gamma_{0} \sin (\omega t)
$$

The response of a surface to harmonic changes in deformation is expressed in the appearance of a harmonic shear stresses delayed in phase relative to the generating deformation

$$
\tau(t)=\tau_{0} \sin (\omega t+\delta),
$$

where $\gamma_{0}$ and $\tau_{0}$ are amplitudes of deformation and stress, respectively; $\omega$ is the oscillation frequency; and $\delta$ is the phase angle (the lag angle or mechanical loss angle).

In this case, the main characteristic of an interfacial layer is the complex 2D elastic modulus measured in shear, $G_{\mathrm{s}}^{*}$, whose value defined as

$$
\left|G_{\mathrm{s}}^{*}\right|=\frac{\tau_{0}}{\gamma_{0}}
$$

The complex elastic modulus (for viscoelastic liquids) can be expressed by the sum of the real and imaginary components,

$$
G_{\mathrm{s}}^{*}=G_{\mathrm{s}}^{\prime}+i G_{\mathrm{s}}^{\prime \prime}=G_{\mathrm{s}}^{\prime}+i \omega \eta_{\mathrm{s}},
$$

where $G_{\mathrm{s}}^{\prime}$ and $G_{\mathrm{s}}^{\prime \prime}$ are the components of the complex modulus (two-dimensional elastic modulus and loss modulus, respectively), which, in general, depend on the oscillation frequency $\omega$, and $\eta_{\mathrm{s}}$ is the surface dynamic viscosity.

$$
G_{\mathrm{s}}^{\prime}=\left|G_{\mathrm{s}}^{*}\right| \cos \delta, \quad G_{\mathrm{s}}^{\prime \prime}=\left|G_{\mathrm{s}}^{*}\right| \sin \delta .
$$

Contributions of elasticity (real component) and dissipative losses (imaginary component) to the complex dynamic modulus are clearly distinguished in Eq. (5). It is evident that the dynamic viscosity is defined as

$$
\eta_{\mathrm{s}}=\frac{G_{\mathrm{s}}^{\prime \prime}}{\omega}
$$

Generally, the $G_{\mathrm{s}}^{*}$ value can be presented as

$$
G_{\mathrm{s}}^{*}(\omega)=G_{\mathrm{surf}, 0}+G_{\mathrm{s}}^{\prime}(\omega)+i G_{\mathrm{s}}^{\prime \prime}(\omega) .
$$

The presence of a constant term $G_{\text {surf, } 0}$ (different from zero) in formula (8) indicates the existence of solid-like properties of the surface layer, in particular the appearance of a structured (ordered, e.g., liquid-crystal) state.

By analogy with the definitions in bulk rheology, the complex dynamic surface shear viscosity $\eta^{*}$

$$
\eta_{\mathrm{s}}^{*}=\frac{G^{*}}{\omega}
$$


can be defined from complex dynamic surface modulus. Moreover, as usual, $\eta^{*}$ is also defined through the real and imaginary components

$$
\eta_{\mathrm{s}}^{*}=\eta_{\mathrm{s}}^{\prime}-i \eta_{\mathrm{s}}^{\prime \prime},
$$

where the real component $\eta_{\mathrm{s}}^{\prime}$ (or simply $\eta_{\mathrm{s}}$ ) is the surface dynamic viscosity which is determined via Eq. (7).The symbol "*" in the expressions cited above indicates that we deal with complex quantities composed of real and imaginary components.

Furthermore, as in definition (1), dimensions of the components of the complex 2D elastic modulus and viscosity are determined due to the fact that the stress refers to a unit length. Then, the dimensions of the components $G_{\mathrm{s}}^{*}$ and $\eta_{\mathrm{s}}^{*}$ are $[\mathrm{N} / \mathrm{m}]$ and $[(\mathrm{N} \mathrm{s}) / \mathrm{m}]$, respectively, in contrast to the dimensions of the components of the complex modulus and dynamic viscosity upon bulk deformations which are expressed as $\left[\mathrm{N} / \mathrm{m}^{2}\right]$ and $\left[(\mathrm{N} \mathrm{s}) / \mathrm{m}^{2}\right]$, respectively.

One more parameter that is useful for the analysis of the viscoelastic properties of interfacial layers (as well as for bulk measurements) is the tangent of mechanical losses $\tan \delta$, which is defined as

$$
\tan \delta=\frac{G_{\mathrm{s}}^{\prime \prime}}{G_{\mathrm{s}}^{\prime}}=\frac{\omega \eta_{\mathrm{s}}^{\prime}}{G_{\mathrm{s}}^{\prime}}
$$

i.e., this parameter characterizes the relative dissipative losses.

When we deal with studies of viscoelastic properties of interfacial layers in the expansion/compression of the surface (i.e. dilational measurements), the 2D elastic modulus $E_{0}$ and $2 \mathrm{D}$ dilational viscosity $\eta_{\mathrm{d}}$ introduced first by Boussinesq [8] are represented as

$$
E_{0}=\frac{d \sigma}{d \ln A},
$$

and

$$
\eta_{\mathrm{d}}=\frac{\Delta \sigma}{d \ln A / d t},
$$

where $\sigma$ is the surface tension and $A$ is the area of the interface (interfacial layer).

Upon the appearance of harmonic (oscillating) changes in the surface area at frequency $\omega$, oscillating changes in the surface tension are observed that proceed with some phase lag due to the viscoelastic properties of the interfacial layer. At low amplitudes of changes in the surface area, the responses (changes in surface tension) are linear and can be expressed as

$$
\begin{gathered}
A(t)=A_{\text {surf }, 0}+A_{0} \sin (\omega t), \\
\sigma(t)=\sigma_{\text {surf }, 0}+\sigma_{0} \sin (\omega t+\delta),
\end{gathered}
$$

where $A_{0}$ and $\sigma_{0}$ are amplitudes of the surface area and surface tension, respectively, and $A_{\text {surf }, 0}$ and $\sigma_{\text {surf }, 0}$ are the values of the surface area and surface tension prior to oscillation, respectively.

In this case, the basic rheological characteristics of an interfacial layer (similarly to the case of shear) include a complex 2D elastic modulus determined upon dilational measurements as

$$
\begin{gathered}
\left|E^{*}\right|=\frac{\sigma_{0}}{\ln A_{0}}, \\
E^{*}(\omega)=E^{\prime}(\omega)+E^{\prime \prime}(\omega)=\frac{d \sigma(t)}{d \ln A(t)} .
\end{gathered}
$$

The $E^{*}$ modulus is expressed via its real and imaginary components, which depend on the oscillation frequency; in this case, the dimension of the components of the complex modulus also is $[\mathrm{N} / \mathrm{m}]$. The real component characterizes the elastic properties of interfacial layer, while the imaginary component describes the viscous properties of the layer. Correspondingly, expression (16) can be rewritten in the following form:

$$
\begin{gathered}
E^{*}(\omega)=E_{\mathrm{d}}(\omega)+i E_{\eta}(\omega)=E_{\mathrm{d}}(\omega)+i \omega \eta_{\mathrm{d}}(\omega), \\
E_{\mathrm{d}}=\left|E^{*}\right| \cos \delta, \quad E_{\eta}=\left|E^{*}\right| \sin \delta,
\end{gathered}
$$

where $E_{\mathrm{d}}$ is the dilational 2D elastic modulus, the value of which is determined by the amplitude of surface tension at a given frequency; additionally, $\eta_{d}$ is the dilational $2 \mathrm{D}$ viscosity, the value of which is determined by the phase angle $\delta$ between generated surface area changes and the response (changes in surface tension) [9]

$$
\eta_{\mathrm{d}}=\frac{E_{\mathrm{d}} \tan \delta}{\omega}
$$

It should be noted that, as in the rheology of bulk media, the values of surface shear viscosity may depend on the shear rate, thus reflecting the non-Newtonian behavior of interfacial layers. The values of shear and dilational dynamic moduli may depend on frequency, thus reflecting relaxation properties of the interfacial layers, as well as on the amplitude of deformation, thus reflecting the nonlinear behavior of the object upon large deformations.

\section{METHODS OF SHEAR RHEOLOGY}

The measurements of the rheological properties of interfacial layers under shear deformations are performed using rotational (torsional) rheometers. This type of devices comprises variants of rotational viscometers (or dynamic rheometers) where shear deformations are generated in thin surface layers. These devices generate broad possibilities for measuring both the shear viscosity and shear viscoelasticity of interfacial layers. The basic scheme of this device is shown in Fig. 1.

In surface rheometers, either the disc (then the cell remains quiescent) or the cell containing solution (then 


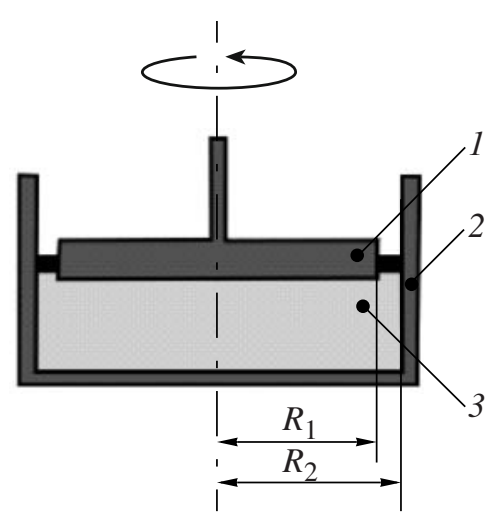

Fig. 1. Scheme of surface rotational rheometer: (1) disc (rotating), (2) cylindrical measuring cell (immovable), and (3) liquid (surfactant solution).

the disc is quiescent) rotate. The main idea of these measurements is that the rigid disc only touches the surface of the solution and the gap $\delta$ between the disc and cell wall $\left(\delta\left(\delta=R_{2}-R_{1}\right)\right)$ is small compared to the disc radius $R_{1}$. In this case (at least, according to the concept of measurements), shear deformations occur in the thin circular gap between the disc and the wall. Then, the torque $T$ divided by the radius (in order to obtain the value of force), which refers to a unit length of the disc, presents the linear tangential stresses and the shear surface viscosity is expressed as

$$
\eta_{\mathrm{s}}=\frac{T\left(R_{2}^{2}-R_{1}^{2}\right)}{2 \pi R_{1}^{2} R_{2}^{2} \Omega}
$$

where $R_{1}$ and $R_{2}$ are the radii of the disc and the cell, respectively, and $\Omega$ is the angular velocity.

If $R_{1} \ll R_{2}$, the scheme corresponds, e. g., to the rotation of a disc in an "infinite" volume (or small disc in a large vessel). Then, the surface viscosity is calculated by the known formula

$$
\eta_{\mathrm{s}}=\frac{T}{4 \pi R_{1}^{2} \Omega} .
$$

The advantage of measuring system with disc radius much smaller than the cell radius consists of the absence of the undesirable effect of the meniscus, which forms between the movable and stationary parts of a device.

Using surface rotational rheometers, the mode of deformation can be set differently, similar to that in ordinary rotational devices, which can include the uniform rotation of the disc (cell) under permanent torque (shear stress) or a preset rate of rotation. In this case, the surface viscosity is measured directly. This mode can also include different oscillations of the disc, i.e., either harmonic or damped. Then, the parameters that charac-

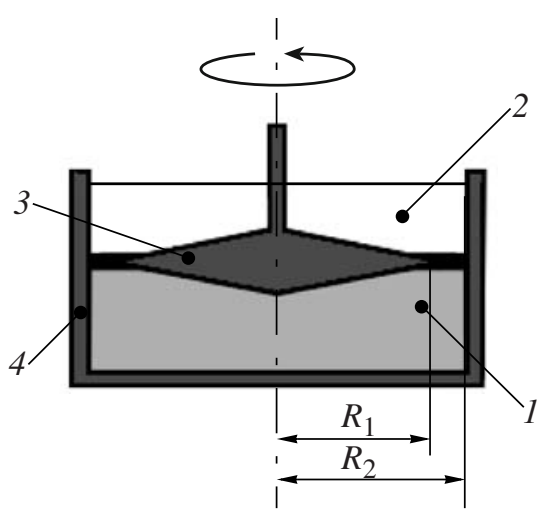

Fig. 2. Scheme of surface rotational rheometer with biconical operating unit: (1) aqueous surfactant solution, (2) apolar liquid, (3) biconical disc, and (4) cylindrical measuring cell.

terize the viscoelastic properties of the sample are measured.

Correspondingly, the surface elastic modulus $G_{\mathrm{s}}$ is found from the following evident relation, which replaces relation $(21)$ :

$$
\frac{T}{2 \pi R^{2}}=G_{\mathrm{s}} \frac{\varphi R_{1}}{\delta}
$$

where $\varphi$ is the angle of disc rotation and $\delta=\left(R_{2}-R_{1}\right)$ is the gap between the stationary (the cell) and rotating (the disc) parts of the measuring system.

The procedures of setting the disc (the cell) in motion and the choice of the corresponding parameters are fully determined by the design of the device and experimentalist's desire. The critical point is the separation of bulk and surface deformations, as the rotation of disc causes the inevitable displacement of the adjacent liquid (solution). A substantial drawback of this specific measuring scheme is the presence of the flat lateral surface of the disc that leads to indefinite end effects.

Therefore, it was proposed to design the disc to resemble a knife-edge [10]. This idea was consistently achieved in the commercial module for a Physica MCR 300 rheometer [11] with bicone geometry with a small angle. In general, a bicone with radius $R_{1}$ can be placed in the interface between two immiscible liquids as shown in Fig. 2.

In this case, formula (22) should be modified in order to take into account the bulk resistance to disc rotation in both viscous media. If the viscosities of these media are denoted by $\eta_{1}$ and $\eta_{2}$, the modified formula for calculating the surface viscosity reads [12]

$$
\eta_{\mathrm{s}}=\frac{T}{4 \pi R^{2} \Omega}-\frac{2 R\left(\eta_{1}+2 \eta\right)}{3 \pi},
$$


i.e., the value

$$
T_{\mathrm{v}}=\frac{8}{3} R^{3}\left(\eta_{1}+\eta_{2}\right) \Omega,
$$

which is represented by the second (negative) term in Eq. (22), takes into account the contribution of bulk flow (torque $T_{\mathrm{v}}$ ) to the total value of measured torque, whereas $\eta_{\mathrm{s}}$ is the viscosity of the layer formed at the interface.

The main problem that arises in the analysis of experimental data consists of the necessity of separating contributions of bulk and surface flows to the measured torque. In some cases, the resistance of the interfacial layer can be more substantial than the losses due to the flow in the bulk.

The contributions of both components to the resistance of disc motion can be expressed using the Boussinesq number (Bo), which can be written as follows:

$$
\mathrm{Bo}=\frac{x_{\mathrm{s}}}{l x_{\mathrm{v}}}
$$

where $x_{\mathrm{s}}$ and $x_{\mathrm{v}}$ are surface and volume properties, respectively, and $l$ is the characteristic length, e.g., the disc radius. For example, $x_{\mathrm{s}}$ can be considered to be surface viscosity $\eta_{\mathrm{s}}$, while $x_{\mathrm{v}}$ can be considered to be ordinary bulk viscosity $\eta$. Then, the Boussinesq number reads

$$
\text { Bo }=\frac{\eta_{\mathrm{s}}}{l \eta} \text {. }
$$

For the scheme shown in Fig. 2, where two viscous liquids are in contact, the Boussinesq number is modified to the following form:

$$
\text { Bo }=\frac{\eta_{\mathrm{s}}}{l\left(\eta_{1}+\eta_{2}\right)} \text {. }
$$

The values of viscosities can be similarly replaced by the values of elastic moduli if we deal with the viscoelastic properties of the bulk and interfacial layer.

At Bo $\gg 1$, the surface resistance dominates over the bulk parameter, the flow in the bulk can be neglected, and the measured resistance can be considered to be a pure surface effect. However, at Bo $\ll 1$, the opposite effect, i.e., the domination of the bulk resistance over the surface friction, is observed.

The value of the Boussinesq number greatly depends on the surface area; formally, it depends on the characteristic length in equation (26). In this respect, the use of both cylindrical and biconical movable elements is unfavorable, since the values of the Boussinesq number becomes small and the role of the bulk flow is significant so that it is necessary to very carefully consider its contributions to the total flow resistance of the movable element of the device.

Simple and obvious procedures for the elimination of the contribution of bulk flow are based on extrapola- tions. These procedures consist of the fact that the torque $T$ is measured at different depths $h$ of immersion of the rotating disc into the liquid bulk, and the obtained $T(h)$ dependence is extrapolated to $h=0$. The thus obtained zero value of the torque $T_{0}$ is treated as a measure of the resistance to the surface deformation, and its values is used to calculate the surface viscosity from Eqs. (21) and (22).

However, a more complete and rigorous analysis requires the methods of continuum mechanics and the consideration of dynamic equilibrium equations. This type of analysis was first performed by Boussinesq [8]. The current analysis of the problem stems from the equilibrium equation formulated by Scriven [13] for the general case of an arbitrary coordinate system

$$
\tau=\left[\sigma+\left(\eta_{\mathrm{d}}-\eta_{\mathrm{s}}\right) \operatorname{div} \bar{V}\right] \bar{P}+2 \eta_{\mathrm{s}} \bar{D},
$$

where $\tau$ is two-dimensional stress tensor; $\sigma$ is the surface tension; $\eta_{d}$ is the surface dilational viscosity; $\eta_{\mathrm{s}}$ is the surface shear viscosity; $\bar{V}$ is the velocity vector; div is the divergence operator; $\bar{P}$ is the tensor, which is projected by each vector on components tangential to the surface; and $\bar{D}$ is the tensor of deformation rate. All values entering Eq. (28) refer to linear surface (but not to bulk) deformations.

This problem was rigorously discussed in [14], where an analytical solution was derived for the velocity distribution in both liquids upon the rotation of both flat and biconical discs. Further analysis was directed at the calculation of the dependence of a dimensionless torque $\tilde{T}$ on the Boussinesq number [15], where $\tilde{T}$ is expressed in the following form:

$$
\tilde{T}=\frac{T}{2 \pi R^{3}\left(\eta_{1}+\eta_{2}\right) \Omega} .
$$

According to the results obtained in [15] by numerical methods, the dependence $\tilde{T}$ (Bo) is characterized by a horizontal asymptote at small values of Bo; moreover, the level of this asymptote depends on the ratio of the viscosities of contacting media, $\tilde{Y}=\eta_{1} / \eta_{2}$. In the limiting case $\tilde{Y} \longrightarrow \infty$; i.e., when we are dealing with the air-solution interface, this asymptote $\tilde{T}=1$. Within a rather wide range of fairly large Bo values, the $\tilde{T}$ (Bo) dependence becomes linear and only then Eq. (29) can be applied. Thus, generalized $\tilde{T}$ (Bo) dependences for different values $\tilde{Y}=\eta_{1} / \eta_{2}$ give a reliable theoretical confirmation for the treatment of measurement results obtained by the rotational method. It should be added that the obtained theoretical results were also generalized to the case of measuring viscoelastic properties of surface layers (dynamic modulus). This result is achieved quite simply, i.e., by replacing the viscosities 
$\eta_{d}$ and $\eta_{s}$ in Eq. (28) for the corresponding complex values.

The theory of calculating the surface shear viscosity and the viscoelastic interfacial properties based on measurements of rotations and oscillations of a disc (cell) at the interface have been also considered earlier in [16-20]. The effect of the emergence of a secondary flow in the bulk of a viscous liquid and its influence on the measured surface viscosity at large values of the Reynolds number was discussed in [21].

Rotational devices of the described type are rather widely used in research practice. For example, as early as in the 1940s, the study of the rheological properties of surfactant interfacial layers became possible due to the development of a unique device by Rehbinder and Trapeznikov [22-27], in which highly sensitive torsion and optical system for the observation of deformations were used as main elements. This torsion viscometer was later employed by Izmailova et al. [4, 28-31] and Abraham et al. [16-18].

An independent version of the considered approach for measuring rheological properties of interfacial layers was the use of bodies of different geometries, in particular, ring (instead of disc) [32] or a system of horizontal coaxial rings with movable inner and static outer rings $[25,33]$. In the latter case, the interfacial layer formed in a narrow gap between the rings is studied [34-39]. By using rings instead of discs, the contribution of the bulk flow is reduced. The theory for this type of rotational rheometer designed for absolute measurements of shear surface viscosity was described in [40]. This method can also be applied when the ring performs damped torsional oscillations, which enables one to estimate both the surface viscosity and the elastic modulus of the interfacial layer [38, 41]. The application of a system of two horizontal coaxial rings enables one to study not only the rheological properties of interfacial layers, but also of free liquid films [42-46].

Another interesting version of rotational surface rheometry is the use of supportless, floating, thin needles or plates placed at the interface and set in motion by an electromagnet [47-49] or freely floating small particles as an indication for the displacement [50]. A comprehensive theoretical analysis of this type of devices and a detailed experimental study of its range of applicability have been reported in [51].

Further development of this technique is related to the application of modern tools for producing a controlled torque or rate of rotation with a corresponding high-precision measurement of stress [15, 52-57]. The description of the design of such modern rotational instruments is beyond the scope of this review. It should only be mentioned that measuring surface viscosity requires the use of highly sensitive measuring devices and a careful elimination of the inherent resistances of all mechanical moving elements and employed transducers. The important element of each design is the motor, which is set in motion by proximity electronics [58]. Monitoring the signals during a complete deformation cycle results in an improved determination of the characteristics of harmonic oscillations [59]. Eventually, experimentalists succeeded in gaining outstanding instrumental results, e.g., the possibility of measuring the amplitude of deformation at a level of $0.1 \mu \mathrm{rad}$ and the torque on the order of $0.01 \mu \mathrm{N} \mathrm{m}[11,15]$.

The employment of rotational instruments seems to be a rather universal technique for determining rheological properties of adsorption layers at liquid interfaces, including viscoelastic layers of proteins and biopolymers [60-68]. Furthermore, the use of the improved experimental instrumentation described above also made it possible to broaden the application of the discussed method to include other systems [69].

\section{METHODS BASED ON THE OSCILLATION OF DROPLETS (BUBBLES)}

The idea of measuring rheological properties via changes in the surface area in order to determine the viscoelastic properties of interfacial layers of surfactants by a biaxial stretching is quite evident. At present, different methods of oscillating droplets (bubbles) based on variations in surface (interfacial) tension as a response to harmonic compressions-expansions of the interfacial area (via variations of the volume of a droplet or bubble) are widely used. The determination of dilational rheological properties of interfacial layers is based on measuring the dynamic interfacial tension during droplet oscillations at a certain frequency (cf. Eqs. (12)-(20)).

These methods have been successfully implemented in various devices, among which we distinguish between two most widespread types. The first of these methods is the drop profile analysis tensiometer, which is used to measure surface tension by analyzing the shape of a droplet (bubble) [70-72], which can be operated in the low-frequency range from $10^{-3}$ to $0.2 \mathrm{~Hz}$. The second device is the capillary pressure tensiometer, which is used to directly measure capillary pressure [73] at higher frequencies of $0.1-100 \mathrm{~Hz}$ (in some cases, up to $500 \mathrm{~Hz}$ ). These devices are summarized in [74]. These methods are limited to a certain maximum frequency due to the appearance of nonradial droplet oscillations, which, for different reasons, appear at higher frequencies of $10^{2}-10^{4} \mathrm{~Hz}$.

It was rigorously demonstrated [75] that the character of an oscillating droplet (bubble) is highly sensitive to the presence of surfactants at the interface. Hence, quantitative characteristics of interfacial layers can be estimated by studying oscillations. However, this idea was only recently realized and introduced into the routine laboratory practice due to the progress in highspeed video techniques and the development of computer processing of the results of measurements that 


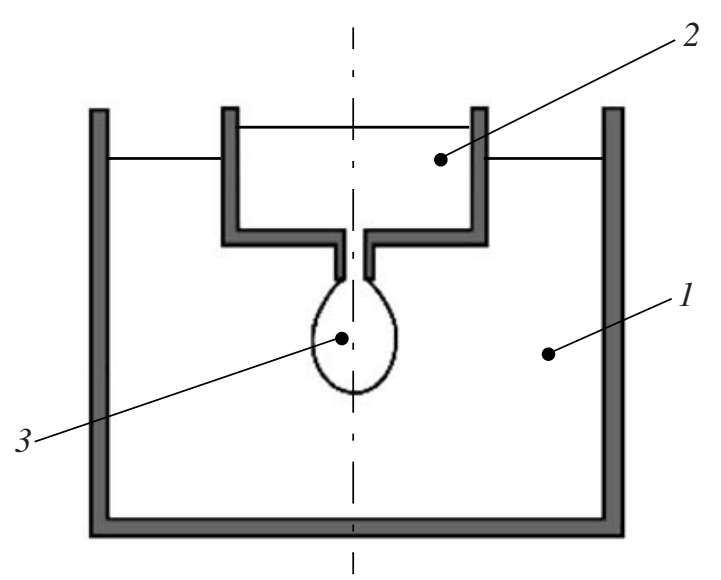

Fig. 3. Basic scheme of measuring cell used in the oscillating droplet (bubble) method: (1) aqueous surfactant solution, (2) apolar liquid/air, and, (3) droplet/bubble.

made it possible to reliably monitor changes in the droplet profile and to perform the necessary calculations $[76,77]$.

An extensive and detailed review devoted to the analysis of droplet shapes has been published recently
[72], so that we only dwell on the common fundamental points. The scheme of measurements is shown in Fig. 4.

A reliable modern experimental unit for studying droplet oscillations was probably for the first time described in [78-80]. Later, numerous variants of this measurement scheme were proposed. The scheme, in which the upper cell was open, was used in [81]. The variant of measurements using a closed upper cell was described in $[82,83]$. The implementation of this method suggests a broad potential for measuring viscoelastic properties of interfacial layers of surfactants, including all classical schemes of relaxation experiments, e.g., periodic deformations [84], as well as the relaxation of interfacial layers induced by transient changes in the surface area of a droplet induced via changes in its volume [85].

The theory of this method would be relatively simple if the droplet had a strictly spherical shape. Then, it would be easy to calculate changes in the volume and, hence, in the surface area upon oscillations. It was demonstrated $[79,86]$ that a droplet (bubble) with an admissible accuracy can be considered spherical provided that its size does not exceed a hemisphere. In this case, oscillations can be considered to be strictly radial.

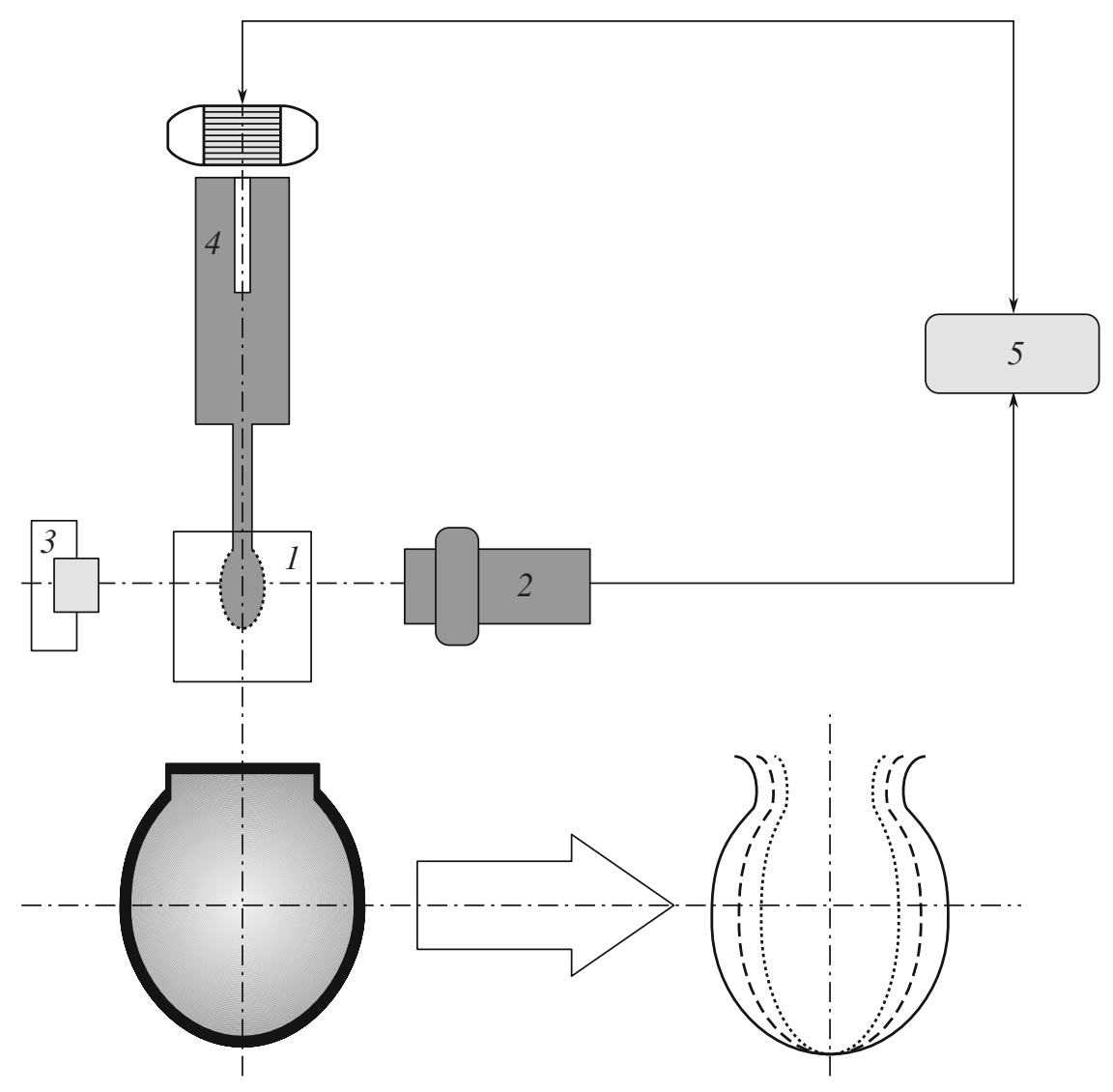

Fig. 4. General scheme for measuring the viscoelastic properties of interfacial layers by the oscillating droplet (bubble) method: (1) measuring cell, (2) video camera, (3) light source, (4) dosing unit, and (5) computer [56]. 
(a)
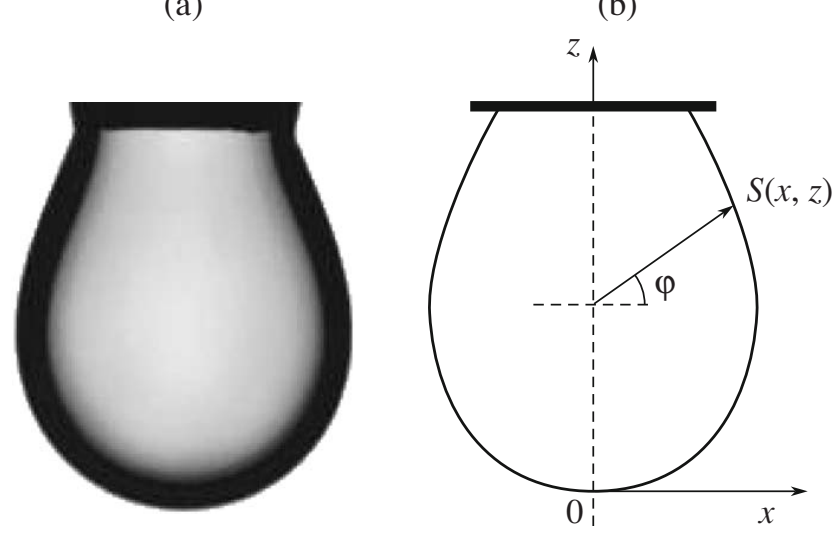

Fig. 5. (a) Real shape of a droplet and (b) calculation scheme [72].

However, there is a substantial difference in the behavior of droplets depending on whether the measuring cell (Fig. 4) is open or closed, as the compressibility of the medium appears to be a significant factor that affects both the shape and stability of the meniscus [87, 88]. Moreover, the character of oscillations depends on whether the size of the bubble is smaller or larger than the hemisphere [89]. Some instrumental errors can be excluded by using a differential method when measurements are performed simultaneously with two droplets (squeezed from neighbor capillaries) of different sizes [90]; this, however, entails other significant drawbacks.

From an experimental point of view, attention should be paid to the general case when the spherical shape of the meniscus cannot be assumed and the droplet acquires a complex (generally speaking, uncertain) shape (Fig. 5a). The discussed method can be adapted to a routine laboratory practice only after the development of corresponding theoretical notions of the droplet shape and its dependence on the properties of the interfacial layer. Figure 5a demonstrates a calculation scheme that corresponds to the shape of a real droplet.

The calculation of the droplet shape is carried out from the condition of equilibrium of forces acting on a droplet surface. It is assumed that the curvature of the surface is determined by the balance of forces; i.e., the difference in interfacial pressures is balanced by the capillary pressure and the following quite evident condition:

$$
P_{\sigma}+\Delta \rho g z=\sigma\left(\frac{1}{R_{1}}+\frac{1}{R_{2}}\right) .
$$

is fulfilled. Here, $P_{\sigma}$ is the capillary pressure on the drop apex, $\Delta \rho$ is the difference in the densities of contacting phases, $g$ is the gravity acceleration; $\sigma$ is the surface tension, and $R_{1}$ and $R_{2}$ are curvature radii in point $S$ in two planes (it is suggested that the droplet is axisymmetric).

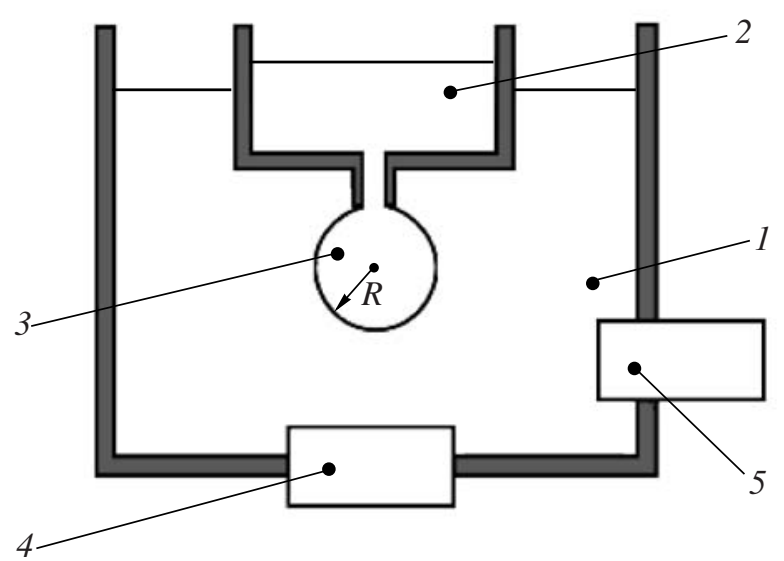

Fig. 6. Basic scheme of a measuring cell used in capillary pressure method with oscillating droplets (bubbles): (1) aqueous surfactant solution, (2) apolar liquid/air, (3) droplet/bubble, (4) piezoelectric element, and (5) pressure transducer.

The force balance for point $S$ of coordinates $(x, z)$ was first formulated and analyzed in [91] where the corresponding version of the Laplace equation was presented in the following form:

$$
\frac{2 \sigma}{R_{0}}+\Delta \rho g z=\sigma\left(\frac{1}{R}+\frac{\sin \varphi}{x}\right)
$$

where $R_{0}$ is the radius of curvature at the droplet apex and $R$ is the radius of curvature of the surface in the point in which principal curvature radii $R_{1}$ and $R_{2}$ are equal; the angle $\varphi$ is counted with reference to this point.

Usually, this equation is considered in a slightly different form, which is derived by the introduction of the form-factor $\beta=\Delta \rho g / \sigma$. Then, the basic equation takes the form

$$
2+R_{0}^{2} \beta\left(z / R_{0}\right)=\left[\frac{1}{\left(R / R_{0}\right)}+\frac{\sin \varphi}{\left(x / R_{0}\right)}\right] .
$$

Under the action of gravity, the droplet can only be strictly spherical when both densities of the phases inside and outside the droplet are equal $(\Delta \rho=0)$ and, hence, the form-factor $\beta=0$.

From the point of view of measuring surface properties, this equation represents the relationships between surface tension and droplet shape. In earlier works, solutions of this equation were presented in tabular form $[92,93]$. In modern instruments, the relation between measured droplet shape and surface tension was established using respective software. The calculation procedure is based on the comparison of the measured profiles with calculated (Laplacian) profiles so that an optimum value of the adjustable parameter is established. Numerical methods of the solution to this problem are reviewed in detail in [72]. 
The method based on measuring capillary pressure upon oscillations of the droplet (bubble) is also widely applied for determining rheological characteristics of interfacial layers [74]. In such type of devices, the pressure drop between the two phases separated by the spherical surface of the droplet (bubble) with radius $R$ is measured under controlled changes in the droplet volume, which makes it possible to determine the surface tension from the simplified Laplace law

$$
\sigma(t)=\frac{P_{\sigma}(t) R(t)}{2}
$$

The scheme of the measuring cell is shown in Fig. 6. The lower cell containing the liquid is closed and equipped with a pressure transducer and a piezoelectric element to induce oscillations in the volume (and, hence, in the surface area) of the droplet formed at the capillary tip and continuously monitored with a video camera. The droplet radius is either measured directly or calculated from the volume of injected liquid. We present no technical details of this method, as they are thoroughly described elsewhere [73]. It should only be emphasized that calculations of this method are based on the fact that the droplet has a spherical shape, which is the result of either its small size or the use of two liquids with a small difference in densities. This method has also been applied successfully to determine the dilational characteristics of interfacial layers under microgravity [94]. The results obtained on the changes in surface tension upon variations in the surface area enable us to calculate the elastic modulus using relation (12).

Relation (12) can easily be generalized to the case of a viscoelastic (damped) response when the changes in surface area (droplet volume) and surface tension are not in phase. Then, the value of elastic modulus $E_{0}$ is substituted by the complex modulus expanded into real and imaginary components; moreover, in general, these components can depend on the oscillation frequency.

It is correctly emphasized that any experimental success with both types of devices is mainly determined by the quality of the used video technique; moreover, image acquisition performed simultaneously with experiment that is especially important when studying transient modes of deformation [95]. Note also that, in the study of transient processes, the ratio of the rates of relaxation and the process that induces changes in the studied properties is important.A theoretical analysis of transient processes, in which the diffusion of surfactant from/to the bulk was assumed to be the main reason for the changes in the interfacial properties, was performed in [96].

In the original version, this technique was successfully applied to studies of kinetic processes resulting in surface tension changes with time [97, 98]. It turned out later that the analysis of video images is a very efficient procedure for studying viscoelastic properties of inter- facial layers, i.e., dependences of the components of the complex elastic modulus on oscillation frequency. Here, it is basically important to ensure a high-speed analysis of deformations, because the oscillation frequency can be fairly high.

When estimating the available frequency range in which the viscoelastic properties can change, it is necessary to take different factors into account. The starting point should be the state when equilibrium interfacial layer is already formed. Then, the method of harmonic oscillations makes it possible to evaluate the properties of this layer. In this respect, the strategy of application of this method in 2D rheology is not essentially different from problems of relaxation spectroscopy, which has been developed extensively and is used in the rheology of polymers $[5,99]$. In any case, with this approach, the range of studied frequencies has no essential limitations. However, purely hydrodynamic restrictions in frequency are possible that are caused by the deviation of the droplet profile from the theoretically expected shape. In this case, the processing of measurement results according to the standard procedure (which was used to develop the software) becomes incorrect [100].

Therefore, it is noted that the droplet oscillation method in the standard version can usually be applied within the low-frequency range confined to an upper frequency of $1 \mathrm{~Hz}[72,100]$. The expansion of potential of the discussed method is related with the use of very small droplets (bubbles) [101]. Nevertheless, in some experiments (under conditions of microgravity), it was possible to form ideally spherical bubbles that avoid experimental problems and allow measurements within a frequency range of up to $100 \mathrm{~Hz}[102,103]$. It was mentioned that the shape of a bubble depends on the ratio between surface forces and viscous drag in the bulk; i.e., as usual, the stability of the bubble shape depends on the capillary number $\mathrm{Ca}$, and distortions of a spherical surface becomes possible at very small $\mathrm{Ca}$ values $(\mathrm{Ca}>0.002)$ [104].

The second approach has gained wider recognition in colloid science when dealing with methods based on droplet (bubble) oscillations for monitoring changes occurring due to various reasons in the interfacial layer. First of all, diffusion phenomena play here a significant role and the characteristic observation time (reciprocal to the oscillation frequency) should therefore be smaller than the characteristic time of diffusion. The same principle, as mentioned above in discussing the relaxation method, is valid in this case. Thus, generally speaking, such approach to the application of an oscillation method inevitably imposes some constraints on the admissible frequency range in which correct results can be obtained.

The first application of the oscillating droplet method for measuring viscoelastic properties of interfacial layers is described in [105]. In subsequent years, 


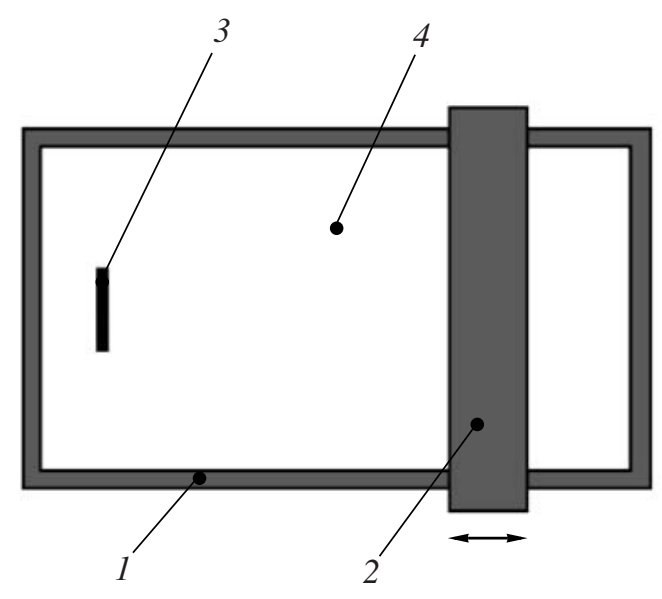

Fig. 7. Scheme of oscillating barrier method: (1) Langmuir trough, (2) movable barrier, (3) Wilhelmy plate, and (4) surfactant film.

this method was repeatedly used to study various systems with different purposes, in particular, to investigate the role of the surfactant nature in the stability of interfacial layers, to study mass exchange processes at the interface, changes in conformations of molecules in the interfacial layers, etc. [69, 106-112].

The application of the oscillation method for measuring the viscoelastic properties of interfacial layers, including nonharmonic and aperiodic oscillations, is closely associated with the use of the Fourier analysis of experimentally measured functions [72]. In this respect, there is a complete analogy with the application of the mechanical Fourier spectroscopy of anharmonic signals considered in $[113,114]$.

At present, the oscillating droplet (bubble) method used for measuring viscoelastic properties of interfacial layers at liquid interfaces is widely applied in the laboratory practice and also realized on a commercial level by a number of companies for producing different instruments [115-117].

\section{OSCILLATING BARRIER METHOD}

The oscillating barrier method [118] is used for studying the dilational behavior of adsorption layers formed by adsorption from a surfactant solution or by spreading a monolayer of an insoluble surfactant. This method and its design are described in detail in [70, 118-121]. The main measuring cell is a Langmuir trough containing the surfactant surface layer restricted on three sides by the trough walls and at the fourth side, by a movable barrier. As a result of the back-and-forth motions of this barrier, compression-expansions of the surface layer are generated and the surface tension is measured by the standard Wilhelmy plate method. The scheme of this method is shown in Fig. 7.
The physical idea of this method is quite evident. Equation (12) is directly used in this method, as changes in the surface tension and surface area at the interface are measured simultaneously with the movement of the barrier. The method makes it possible to measure both the static values of the elastic modulus and the dynamic modulus, provided that the barrier is subjected to oscillations. The complex modulus is calculated from the ratio of oscillation amplitudes of surface tension and surface area of the interfacial layer (see relation (16)). The dilational 2D elastic modulus is calculated using relation (19) and taking into account the phase shift between oscillations of two aforementioned parameters. Although the measurement of surface tension by the Wilhelmy plate is, in principle, a static method, it remains applicable at relatively low oscillation frequencies of the movable barrier. Therefore, the discussed method of an oscillating barrier is used at oscillation frequencies not higher than $0.2 \mathrm{~Hz}$ $[118,122]$. The method was applied in [123-127] and discussed in detail in a recent review [128].

Despite the evident character of measuring scheme, the application of this method requires very accurate measurements of surface tension and barrier displacement. Thus, as far as practical applications are concerned, the oscillating barrier method is inferior, e.g., to the torsional oscillation method, which can be very easily automated. Nevertheless, this method continues to be applied.

\section{CAPILLARY WAVES}

The emergence of capillary waves is a well-known, routine phenomenon observed on liquid surfaces called in every day life "ripple waves." These waves appear under the action of small disturbances and their existence and characteristics are related to the action of surface forces. Low amplitudes and length are typical for capillary waves; therefore gravity does not play a substantial role in the existence of capillary waves, in contrast to the steep sea waves, which are explained, first of all, by gravity [75, 129].

A quantitative study of the effect of surface layers on the wave motion of liquids was started probably in [130]. Even in earlier theoretical studies [75, 131, 132], it was mentioned that the effect of the surface is correlated to the expansion-compression of the surface layer that is equivalent to a certain surface viscosity, although this conception was not used directly. Surface tension forces appear due to the considerable differences in the curvature at the ridge of a wave and wave depression. The current theory of capillary waves is fairly developed and described in many publications [133, 134].

Methods of surface rheology mentioned above, such as the oscillating droplet (bubble) and oscillating barrier method, are limited in oscillation frequency and used at low frequencies. Hence, the capillary wave 


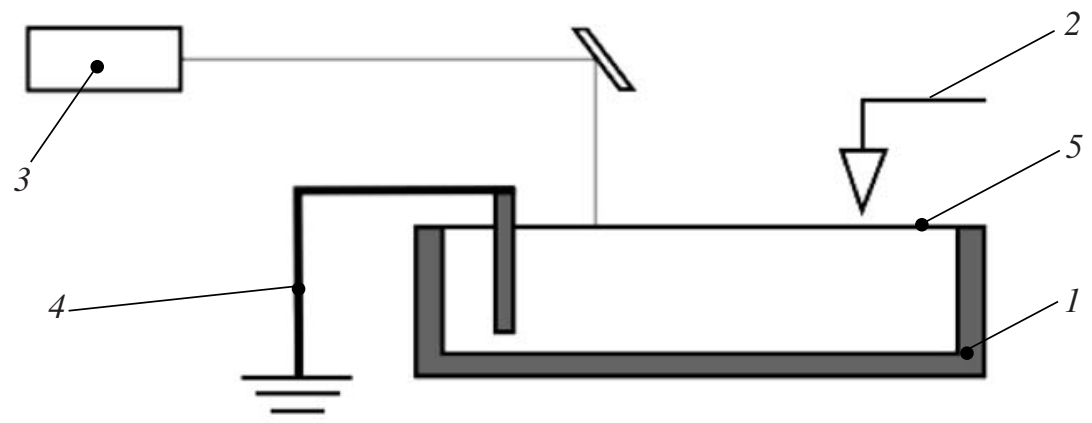

Fig. 8. Possible scheme of actuation and observation for capillary waves: (1) measuring cell, (2) motor for generating capillary waves, (3) optical system for monitoring capillary waves, (4) electrode, and (5) surfactant film.

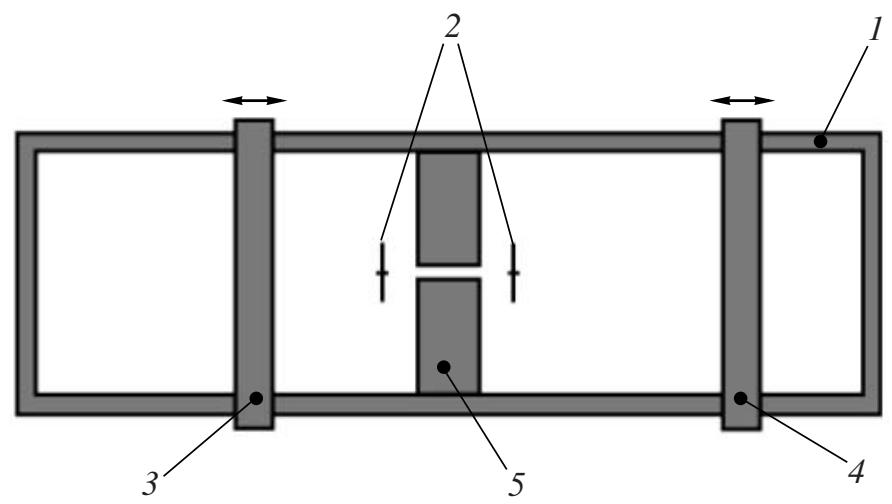

Fig. 9. Scheme of channel viscometer: (1) Langmuir trough, (2) Wilhelmy plates, (3) and (4) movable barriers, and (5) immovable barrier with microchannels.

method is used for studying the dilational behavior of surfactant interfacial layers in the high-frequency range (up to $1000 \mathrm{~Hz}$ ).

From an experimental point of view, for the realization of the capillary wave method, it is necessary to solve two problems, i.e., the development of a procedure for exciting the wave motion and the development of a method for measuring motion of the waves. It is possible to produce both transverse [135-139] and longitudinal [140-149] wave oscillations; in this case, the experimental scheme remains essentially the same. In both cases, it is sufficient to reliably measure the characteristics of the wave process, i.e., oscillation amplitude and damping coefficient.

Some experimental designs are described in [90, 118, 150-152]. Capillary waves are created either by using an electric generator [153] and initiating them with a thin blade arranged above the liquid surface (Fig. 8 ) or by using a mechanical generator [150]. Oscillations can also be created by a periodic displacement of the cell containing the system under study $[154,155]$. In the majority of cases, the motion of arising waves is monitored via contactless optical systems [153, 155157].
Fundamental advantage of the wave damping methods is the fact that measurements are performed by a contactless procedure so that the surfactant interfacial layer is not subjected to any external perturbations. The method of measuring surface properties via capillary waves was used in a number of works when studying insoluble monolayers of surfactants and polyelectrolyte solutions (e.g., see [158-162]).

It is of interest that a wave regime of flow also arises in thin liquid films flowing down the surface of a vertical solid. Here, the crucial role also belongs to surface forces, thus indicating that the capillary mechanism of flow is realized in this case as well [163].

\section{OTHER METHODS}

Various versions of the realization of flow of a Langmuir films through narrow channels gained widespread application in laboratory practice. Two types of flow are distinguished, including the flow induced by surface pressure (pressure driven flows) or by the displacement of a solid wall at which the liquid film is deposited (drag flows). 


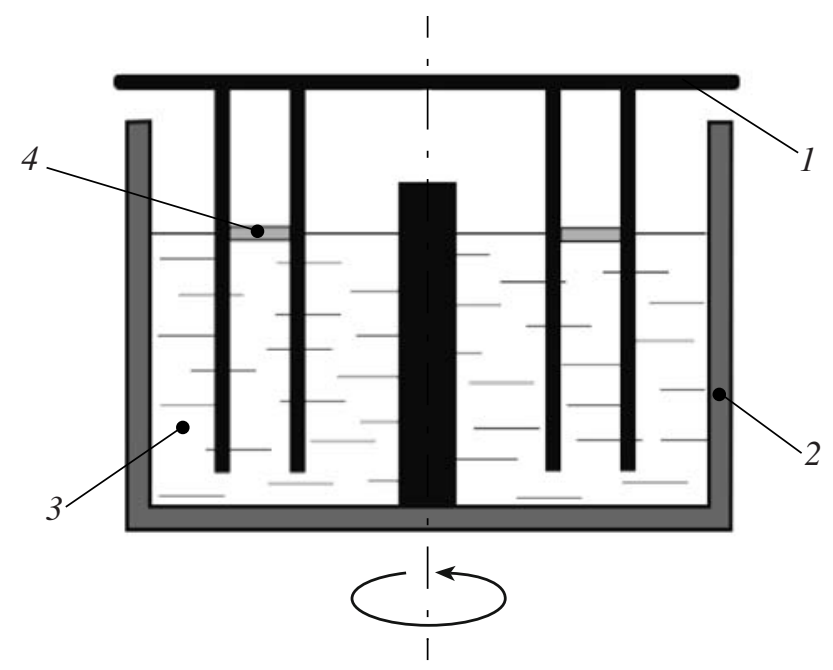

Fig. 10. Scheme of deep channel surface viscometer: (1) immovable part of instrument, (2) rotating vessel, (3) liquid, and (4) surfactant interfacial layer.

With a capillary flow, the surfactant monolayer flows on a free liquid surface due to the applied surface pressure through the narrow gap; in this case, the velocity of flowing liquid is measured as the analog of a Poiseuille flow. This scheme of deformation is sometimes called a Marangoni flow. The experimental units are described elsewhere (cf. [164-167]); the general solution to the problem of joint flow at the surface and in the bulk at arbitrary ratios of viscosities was proposed in [168].

According to this method, a Langmuir film is formed at the liquid surface between two barriers (immovable and movable); a membrane with narrow microscopic channels is placed between these barriers. Upon the displacement of the movable barrier, the monolayer is pressed through these channels and the velocity profile is measured by some optical methods. The character of motion can be monitored by the displacement of markers placed into the flowing surface. The velocity profile depends on the ratio between bulk and surface flows $[165,168]$. Note that this method made it possible to discover the non-Newtonian behavior of a surface layer, i.e., the dependence of apparent surface viscosity on the flow rate [165].

The method of thin-film deformation induced by the motion of an interfacial layer is also described in [169172 ], in which the authors were dealing with a channeltype rheometer (Fig. 9).

When speaking of the drag flows of thin layers caused by the motion of a boundary, it should be mentioned that the historic priority belongs to Derjaguin's works $[173,174]$. This method was realized by Kusakov $[175,176]$ as it applies to measuring rheological properties of thin films deformed by an airflow created above the film surface.
The idea of measuring the resistance to the displacement of very small particles at the surface of a liquid as a procedure for determining its surface viscosity was applied in [177] by measuring the force needed to displace a small sphere on the surface. This method can be considered to be a certain analog of the classical Stokes method for measuring bulk viscosity.

The measurement methods described above continue to dominate and are widely applied for measuring the rheological properties of surfaces and interfacial adsorption layers. However, other approaches are sometimes mentioned in the literature, though some of them are considered old-fashioned. Nevertheless, the procedure of measuring viscoelastic properties of a surface by the observation for the kinetics of a rising liquid over thin wires is described in [153]. The driving force of this process is the electrostatic field caused by the voltage on the wire. A modification of the classical ring detachment method can be used (Du Noüy method) in which the ring is replaced by a wire and the kinetics of the motion of liquid layer detached from the surface and the dynamics of capillary motion of the thin film are monitored [178].

The so-called "deep channel surface viscometer" is described in a number of works. This viscometer is designed as follows (Fig. 10). The outer and inner cylinders are immovable and the bottom is rotated at constant angular velocity so that the flow occurs in a relatively narrow circular gap. The monolayer of an insoluble surfactant to be studied is placed at the interface in this gap.

The flow character depends on the Reynolds number. At low flow rates, the governing factor is the surface shear viscosity; high rates of bottom rotation give rise to secondary flows. Therefore, the monolayer, which is first uniformly distributed over the surface, moves toward the inner cylinder [179-181]. The quantitative theory of this method based on the numerical solution of Scriven's equation (28) was developed in works cited above.

The evaluation of the properties of interfacial layers is based on the direct measurements of the velocity distribution over the surface by using different procedures. In particular, tracers are placed on the surface, as described in [182-184]. Of special interest is the review [184], where various modern rheometry methods are considered.

Deep channel surface viscometers have been successfully applied in a number of works [183, 185], although some difficulties have been mentioned when studying systems in which surfactant was partially soluble in liquid [186]. However, this remark is applicable to almost any measurement method. 


\section{CONCLUSIONS}

Surfactants play a crucial role in manufacturing a large number of items in the food industry, biotechnology, in the production of drugs and cosmetics, etc., which present primarily disperse systems and their properties depend on the properties of the involved interfaces, thus giving rise to the problem of a tailored optimal choice of necessary components. This problem can only be solved on the basis of a description and understanding of the phenomena occurring at the interface, which, in turn, requires knowledge of quantitative characteristics of the rheological properties of the interfacial layers. In this review, we attempted to consider the current notions of experimental procedures of the measurement of these properties devoted precisely to this problem.

The discussed experimental methods are based on the general concept that surface (interfacial) layers of surfactants are two-dimensional objects and their properties are characterized by surface viscosity and elasticity, i.e., viscoelasticity. Similar to the viscoelastic properties of bulk (three-dimensional) material, these characteristics represent (in the linear region of mechanical behavior) the frequency dependences of the components of complex elastic modulus (or complex viscoelasticity); in the nonlinear region, amplitude-dependent components of dynamic functions must be added to these characteristics. In the stationary state of a system, surface viscosity and equilibrium elastic modulus are used as characteristics of interfacial layers.

At present, two basic approaches to the experimental determination of the rheological properties of twodimensional objects received widespread use, namely, rotational $2 \mathrm{D}$ rheometry and dilational rheometry.

In the first case, disturbances are created on the surface in a thin interfacial layer by either the stationary rotation of a solid in contact with the surface or by its periodic oscillations. The processing of the dependence of the measured torque on the surface deformation is based on an analysis of the dynamic equations that yield the values of the 2D shear characteristics of the surface such as shear viscosity and shear elastic modulus. Furthermore, 2D shear viscosity, in principle, can depend on the rate of deformation, i.e., on the twodimensional structure of the interfacial layer, as well as bulk medium, and, hence, can exhibit non-Newtonian properties.

In the second case, upon the oscillations (expansion-compression) of the surface of a droplet (bubble), the area of the interfacial layer covered by surfactants is subjected to changes, thus generating changes in the surface tension. The ratio between these changes in surface tension and surface area makes it possible to calculate the 2D dilational characteristics of the surface, i.e., the viscosity and elastic modulus.
It is significant that, in 2D rheology, the shear and dilational characteristics of the interfacial layers are considered as independent parameters, although, in the rheology of three-dimensional media, there are certain quantitative relationships, at least in the linear region of the mechanical behavior of the studied object.

It is these two approaches that constitute the basis of modern experimental methods of 2D rheology. These approaches have been strictly substantiated theoretically, incorporated into experimental units operating in many laboratories, and have been implemented in a number of commercial instruments.

Among the experimental methods, attention is focused on the study of low-scale surface (capillary) waves, as this approach makes it possible to make progress in the region of high-frequency oscillations, which can be very promising as it applies to the simulation of atmospheric, oceanographic, and other phenomena.

\section{REFERENCES}

1. Shchukin, E.D., Pertsov, A.D., and Amelina, E.A., Kolloidnaya khimiya (Colloid Chemistry), Moscow: Vysshaya Shkola, 2004. (Shchukin, E.D., Pertsov, A.D., Amelina, E.A., and Zelenev, A.S., Colloid and Surface Chemistry, Möbius, D. and Miller, R., Eds., Amsterdam: Elsevier, 2001, vol. 12).

2. Krotov, V.V, in Studies in Interface Science, Liggieri, L., Möbius, D., and Miller, R., Eds., Amsterdam: Elsevier, 2008.

3. Krotov, V.V. and Rusanov, A.I., Physicochemical Hydrodynamics of Capillary Systems, London: Imperial College Press, 1999.

4. Izmailova, V.N., Yampol'skaya, G.P., and Summ, B.D., Surfaces Phenomena in Protein Systems, Moscow: Khimiya, 1988.

5. Malkin, A.Ya. and Isayev, A., Rheology: Conceptions, Methods, Applications, Toronto: ChemTec, 2006.

6. Plateau, J., Nuovo Cimento, Ser. 2, 1872, vols. 5-6, p. 239.

7. Gibbs, J.W., Collected Works, New York: Longmans, 1928, vol. 1.

8. Boussinesq, M.J., Ann. Chim. Phys., 1913, vol. 29, p. 349.

9. Lucassen-Reynders, E.H., in Anionic Surfactant: Physical Chemistry of Surfactant Action, Lucassen-Reynders, E.H., Ed., New York-Basel: Marcel Dekker, 1981, p. 1.

10. Lifshutz, N., Hedge, M.G., and Slattery, J.C., J. Colloid Interface Sci., 1971, vol. 37, p. 73.

11. Anton Paar GmbH. Interfacial Rheology System (MCR$I R S)$, http://www.anton-paar.com

12. Goodrich, F.C. and Chatterjee, A.K., J. Colloid Interface Sci., 1970, vol. 34, p. 36.

13. Scriven, L.E., Chem. Eng. Sci., 1960, vol. 12, p. 98.

14. Oh, S.G. and Slattery, J.C., J. Colloid Interface Sci., 1978, vol. 67, p. 516. 
15. Erni, Ph., Fischer, P., Windhab, E.J., et al., Rev. Sci. Instrum., 2003, vol. 74, p. 4916.

16. Abraham, B.M., Miyano, K., Xu, S.Q., and Katterson, J.B., Phys. Rev. Lett., 1982, vol. 49, p. 1643.

17. Abraham, B.M., Miyano, K., Katterson, J.B., and Xu, S.Q., Phys. Rev. Lett., 1983, vol. 51, p. 1975.

18. Abraham, B.M. and Katterson, J.B., Langnuir, 1985 , vol. 1, p. 708.

19. Joos, P., Rheol. Acta, 1971, vol. 10, p. 138.

20. Barentin, C., Ybert, C., De Meglia, J.-M., and Joanny, J.-F., J. Fluid Mech., 1999, vol. 397, p. 331.

21. Hirsa, A.A., Lopez, J.M., and Miraghaie, R., J. Fluid Mech., 2001, vol. 443, p. 271.

22. Rehbinder, P.A. and Trapeznikov, A.A., Zh. Fiz. Khim., 1938, vol. 12, p. 573.

23. Trapeznikov, A.A., Dokl. Akad. Nauk SSSR, 1941, vol. 30, p. 319.

24. Trapeznikov, A.A., in Vyazkost' zhidkostei i kolloidnykh rastvorov (Viscosity of Liquids and Colloid Solutions), 1941, vol. 67, no. 1, p. 87.

25. Trapeznikov, A.A., Zh. Fiz. Khim., 1945, vol. 19, p. 229.

26. Rehbinder, P.A., in Novye metody fiziko-khimicheskikh issledovanii poverkhnostnykh yavlenii (New Methods of Surface Phenomena Investigation), 1950, vol. 5, no. 1.

27. Izmailova, V.N. and Rehbinder, A.A., Strukturoobrazovanie $v$ belkovykh sistemakh (Structuring in Protein Systems), Moscow: Khimiya, 1974.

28. Izmailova, V.N. and Yampol'skaya, G.P., in Fizikokhimicheskaya mekhanika $i$ liofil'nost' dispersnykh sistem (Physicochemical Mechanics and Lyophilicity of Disperse Systems), Kiev: Naukova Dumka, 1979, vol. 11, p. 63.

29. Izmailova, V.N., Angarska, Zh.K., Yampol'skaya, G.P., and Tulovskaya, Z.D., Kolloidn. Zh., 1980, vol. 42, p. 5554.

30. Izmailova, V.N., Nefedova, E.N., Tulovskaya, Z.D., and Yampol'skaya, G.P., Kolloidn. Zh., 1981, vol. 43, p. 161.

31. Izmailova, V.N., Levachev, S.M., Yampol'skaya, G.P. et al., Kolloidn. Zh., 2000, vol. 62, p. 70.

32. Moules, C., Abstracts of Papers, 3 Rim Pacific Conf., Vancouver, 2001, p. 137.

33. Zotova, K.V. and Trapeznikov, A.A., Kolloidn. Zh., 1965, vol. 27, p. 197.

34. Izmailova, V.N., Derkach, S.R., Zotova, K.V., and Danilova, R.G., Kolloidn. Zh., 1993, vol. 55, p. 54.

35. Izmailova, V.N., Derkach, S.R., Levachev, S.M., et al., Kolloidn. Zh., 1994, vol. 56, p. 751.

36. Izmailova, V.N., Derkach, S.R., Yampol'skaya, G.P., et al., Kolloidn. Zh., 1997, vol. 59, p. 603.

37. Izmailova, V.N., Derkach, S.R., Levachev, S.M., et al., Zh. Nauchn. Prikl. Fotogr. Kinematogr., 2000, vol. 45, no. 5 , p. 6.

38. Izmailova, V.N., Derkach, S.R., Levachev, S.M., et al., Kolloidn. Zh., 2000, vol. 62, p. 725.
39. Grigoriev, D.O., Derkach, S.R., Krägel, J., and Miller, R., Food Hydrocolloids, 2007, vol. 21, p. 823.

40. Goodrich, F.C., Allen, L.H., and Chatterjee, A.K., Proc. R. Soc. London, A, 1971, vol. 320, p. 537.

41. Kuhnhenn, V., Krägel, J., Horstmann, U., and Miller, R., Colloids Surf., B, 2006, vol. 47, p. 29.

42. Derkach, S.R., Izmailova, V.N., Zotova, K.V., and Pyleva, Yu.V., Kolloidn. Zh., 1994, vol. 56, p. 751.

43. Derkach, S.R., Izmailova, V.N., Tarasevich, B.N., et al., Zh. Nauchn. Prikl. Fotogr. Kinematogr., 1997, vol. 42, no. 1, p. 54.

44. Derkach, S.R., Izmailova, V.N., and Petrova, L.A., Zh. Nauchn. Prikl. Fotogr. Kinematogr, 1998, vol. 43, no. 2, p. 40.

45. Derkatch, S.R., Petrova, L.A., Izmailova, V.N., and Tarasevitch, B.N., Colloids Surf., A, 1999, vol. 152, p. 189.

46. Derkach, S., Levachev, S., Izmailova, V., and Ivanov, Ya., Tekh. Misul, 2000, vol. 37, nos. 1-2, p. 69.

47. Brooks, C.F., Fuller, G.G., Frank, C.W., and Robertson, C.R., Langmuir, 1999, vol. 15, p. 2459.

48. Brooks, C.F., Thiele, J., Frank, C.W., et al., Langmuir, 2002, vol. 18, p. 2166.

49. Ding, J., Warriner, H.E., Zasadzinski, J.A., and Schwartz, D.K., Langmuir, 2002, vol. 18, p. 2800.

50. Furmakov, E.F., in Fundamentalnye problemy estestvoznaniya i tekhniki (Fundamental Problems of Natural Science and Engineering), 2005, no. 30, p. 1.

51. Reynaert, S., Brooks, C.F., Moldenaers, P., et al., J. Rheol., 2008, vol. 52, p. 261.

52. Erni, Ph., Fischer, P., Heyer, P., et al., Prog. Colloid Polym. Sci., 2004, vol. 129, p. 16.

53. Ray, Y.-C., Lee, H.O., and Jiang, T.-S., J. Colloid Interface Sci., 1987, vol. 119, p. 81.

54. Lee, H.O., Hang, T.-S., and Avramidis, K.S., J. Colloid Interface Sci., 1991, vol. 146, p. 90.

55. Krägel, J., Siegel, J., Miller, R., et al., Colloids Surf., A, 1994, vol. 91, p. 169.

56. Miller, R., Wüstneck, R., Krägel, J., and Kretzschmar, G., Colloids Surf., A, 1996, vol. 111, p. 75.

57. Nagarajan, R., Chung, S.I., and Wasan, D.T., J. Colloid Interface Sci., 1998, vol. 294, p. 53.

58. Läuger, J. and Huch, S., Abstracts of Papers, XIII Int. Conf. on Rheology, Cambridge, 2000, p. 11.

59. Läuger, J., Wollny, K., and Huch, S., Rheol. Acta, 2002, vol. 41, p. 356.

60. Izmailova, V.N, in Progress in Surface and Membrane Science, Cadenhead, D. and Danielli, F.J., Eds., New York: Academic, 1979, p. 143.

61. Izmailova, V.N., Yampol'skaya, G.P., and Tulovskaya, Z.D., Kolloidn. Zh., 1998, vol. 60, p. 598.

62. Izmailova, V.N. and Yampolskaya, G.P., Colloids Surf., A, 1998, vol. 142, p. 125.

63. Izmailova, V.N. and Yampolskaya, G.P., Adv. Colloid Interface Sci., 2000, vol. 88, p. 99.

64. Izmailova, V.N. and Yampolskaya, G.P., Appl. Mech. Eng., 4 Special Issue: ICER'99, 1999, p. 141. 
65. Graham, D.E. and Philips, M.C., J. Colloid Interface Sci., 1980, vol. 76, p. 240.

66. Dickinson, E., Murray, B.S., and Stainsby, G., J. Colloid Interface Sci., 1985, vol. 106, p. 259.

67. Dickinson, E., Colloids Surf., B, 2001, vol. 20, p. 197.

68. Erni, Ph., Fischer, P., and Windhab, E.J., Appl. Phys. Lett., 2005, vol. 87, p. 244104.

69. Erni, Ph., Fischer, P., and Windhab, E.J., Langmuir, 2005, vol. 21, p. 10555.

70. Noskov, B.A., Akentiev, A.V., Bilibin, A.Yu., et al., Langmuir, 2004, vol. 20, p. 9669.

71. Noskov, B.A., Akentiev, A.V., and Miller, R., J. Colloid Interface Sci., 2002, vol. 255, p. 417.

72. Loglio, G., Pandolfini, P., Miller, R., et al., in Novel Methods to Study Interfacial Layers, Möbius, D. and Miller, R., Eds., Amsterdam: Elsevier, 2001, p. 440.

73. Miller, R., Fainerman, V.B., and Kovalchuk, V.I., in Encyclopedia of Surface and Colloid Science, Hubbard, A., Ed., New York: Marcel Dekker, 2002, p. 814.

74. Ravera, F., Ferrari, M., Santini, E., and Liggieri, L., $A d v$. Colloid Interface Sci., 2005, vol. 117, p. 75.

75. Levich, V.G., Fiziko-khimicheskaya gidrodinamika (Physicochemical Hydrodynamics), Moscow: Fizmatgiz, 1959.

76. Rusanov, A.I and Prokhorov, V.A., in Studies of Interface Science, Möbius, D. and Miller, R.V., Eds., Amsterdam: Elsevier, 1996, vol. 3.

77. Chen, P., Kwok, D.Y., Prokop, R.M., et al., in Studies of Interface Science, Möbius, D. and Miller, R.V., Eds., Amsterdam: Elsevier, 1998, p. 61.

78. Kretzschmar, G. and Lunkenheimer, K., Ber. BunsenGes. Phys. Chem., 1970, vol. 74, p. 107.

79. Lunkenheimer, K. and Kretzschmar, G., Z. Phys. Chem. (Leipzig), 1975, vol. 256, p. 593.

80. Slama, H., Schoedel, W., and Hansen, E., Pfluegers Arch., 1971, vol. 322, p. 355.

81. Passarone, A., Liggieri, L., Rando, N., et al., J. Colloid Interface Sci., 1991, vol. 146, p. 152.

82. Fruhner, H. and Wantke, K.-D., Colloids Surf., A, 1996, vol. 114, p. 53.

83. Wantke, K.-D. and Fruhner, H., J. Colloid Interface Sci., 2001, vol. 237, p. 185.

84. Benjamins, J., Cagna, A., and Lucassen-Reynders, E.H., Colloids Surf., A, 1996, vol. 114, p. 245.

85. Miller, R., Sedev, R., Schano, K.-H., et al., Colloids Surf., A, 1993, vol. 69, p. 209.

86. Lunkenheimer, K., Hartenstein, C., Miller, R., and Wantke, K.-D., Colloids Surf., 1984, vol. 8, p. 271.

87. Kovalchuk, V.I., Zholkovsij, E.K., Krägel, J., et al., J. Colloid Interface Sci., 2000, vol. 224, p. 245.

88. Kovalchuk, V.I., Krägel, J., Miller, R., et al., J. Colloid Interface Sci., 2000, vol. 232, p. 25.

89. Kovalchuk, V.I., Krägel, J., Makievski, A.V., et al., J. Colloid Interface Sci., 2000, vol. 252, p. 433.

90. Fainerman, V.B., Mys, V.D., Makievski, A.V., and Miller, R., J. Colloid Interface Sci., 2006, vol. 304, p. 222.

COLLOID JOURNAL Vol. $71 \quad$ No. $1 \quad 2009$
91. Bashforth, F. and Adams, J.C., An Attempt to Test the Theories of Capillary Action, Cambridge: Cambridge Univ. Press, 1883.

92. Fordham, S., Proc. R. Soc. London, A, 1948, vol. 194, p. 1.

93. Hartland, S. and Hartley, R., Axisymmetric Fluid-Liquid Interactions, Amsterdam: Elsevier, 1976.

94. Miller, R., Grigoriev, D.O., Krägel, J., et al., Microgravity Sci. Technol. J., 2006, vol. 18, p. 104.

95. Dukhin, S.S., Kretzschmar, G., and Miller, R., in Studies of Interface Science, Möbius, D. and Miller, R.V., Eds., Amsterdam: Elsevier, 1995.

96. Miller, R., Loglio, G., Tesei, U., and Schano, K.-H., Adv. Colloid Interface Sci., 1991, vol. 37, p. 73.

97. Miller, R., Krägel, J., Makievski, A.V., et al., Abstracts of Papers, 2 World Emulsion Congr., Bordeaux, 1997, vol. 4, p. 153.

98. Makievski, A.V., Fainerman, V.B., and Miller, R., Abstracts of Papers, 2 World Emulsion Congr., Bordeaux, 1997, vol. 2, p. 288.

99. Ferry, J.D., Viscoelastic Properties of Polymers, New York: Wiley, 1961.

100. Leser, M.E., Acquistapace, S., Magna, A., et al., Colloids Surf., A, 2005, vol. 261, p. 25.

101. Wanke, K.-D. and Fruhner, H., J. Colloid Interface Sci., 2001, vol. 237, p. 185.

102. Kovalchuk, V.I., Krägel, J., Makievski, A.V., et al., J. Colloid Interface Sci., 2004, vol. 280, p. 498.

103. Krägel, J., Kovalchuk, V.I., Makievski, A.V., et al., Microgravity Sci. Technol. J., 2005, vol. 16, p. 186.

104. Freer, E.M., Wong, H., and Radke, C.J., J. Colloid Interface Sci., 2005, vol. 282, p. 128.

105. Loglio, G., Miller, R., Stortini, A.M., et al., Colloids Surf., A, 1995, vol. 95, p. 63.

106. Loglio, G., Pandolfini, P., Tesei, U., and Noskov, B., Colloids Surf., A, 1998, vol. 143, p. 301.

107. Ortegren, J., Wantke, K.-D., and Motschmann, H., Rev. Sci. Instrum., 2003, vol. 74, p. 5167.

108. Stubenrauch, C. and Miller, R., J. Phys. Chem., B, 2004, vol. 108, p. 6412.

109. Liggieri, L., Ferrari, M., Mondelli, D., and Ravera, F., Faraday Discuss. Chem. Soc., 2005, vol. 129, p. 125.

110. Golding, M. and Sein, A., Food Hydrocolloids, 2004, vol. 18, p. 451.

111. Benjamins, J., Lyklema, J., and Lucassen-Reynders, E.H., Langmuir, 2006, vol. 22, p. 6181.

112. Aksenenko, E.V., Kovalchuk, V.I., Fainerman, V.B., and Miller, R., Adv. Colloid Interface Sci., 2006, vol. 122, p. 57.

113. Malkin, A.Ya., Begishev, V.P., and Mansurov, V.A., Vysokomol. Soedin., Ser. A, 1984, vol. 26, p. 869.

114. Malkin, A.Ya., Rheol. Acta, 2004, vol. 43, p. 1.

115. KSV Instruments (Finland), www.ksvltd.com

116. I.T.Concept (France), itsonsertfr.som, Trasker instrument.

117. SINTERFACE Technologies (Germany), RAT1 instrument. 
118. Noskov, B.A., Akentiev, A.V., Bilibin, A.Yu., et al., Adv. Colloid Interface Sci., 2003, vol. 104, p. 245.

119. Lucassen, J. and Van den Tempel, M., Chem. Eng. Sci., 1972, vol. 27, p. 1283.

120. Lucassen, J. and Giles, D., J. Chem. Soc., Faraday Trans. 1, 1975, vol. 71, p. 217.

121. Kretzschmar, G., Prog. Colloid Polym. Sci., 1988, vol. 77, p. 72.

122. Akent'ev, A.V. and Noskov, B.A., Kolloidn. Zh., 2002, vol. 64, p. 129.

123. Krägel, J., Kretzschmar, G., Li, J.B., et al., Thin Solid Films, 1996, vols. 284-285, p. 361.

124. Monroy, F., Ortega, F., and Rubio, R.G., Phys. Rev. E: Stat. Phys., Plasmas, Fluids, Relat. Interdiscip. Top., 1998, vol. 58, p. 7629.

125. Noskov, B.A., Akentiev, A.V., and Miller, R., J. Colloid Interface Sci., 2002, vol. 255, p. 417.

126. Murray, B.S. and Nelson, P.V., Langmuir, 1996, vol. 12, p. 5953.

127. Jiang, Q. and Chiew, Y.C., Colloids Surf., B, 2001, vol. 20 , p. 303.

128. Blinov, L.M., Usp. Fiz. Nauk, 1988, vol. 155, p. 443.

129. Lamb, H., Hydrodynamics, New York: Dover, 1932.

130. Aitken, J., Proc. R. Soc. Edinburgh, 1883, vol. 12, p. 56.

131. Levich, V.G., Zh. Eksp. Teor. Fiz., 1940, vol. 10, p. 1296.

132. Levich, V., Acta Physicochim. URSS, 1941, vol. 14, p. 307.

133. Lucassen-Reynders, E.H. and Lucassen, J., Adv. Colloid Interface Sci., 1969, vol. 2, p. 347.

134. Bock, E.J., J. Colloid Interface Sci., 1991, vol. 147, p. 422.

135. Hansen, R.S. and Mann, S.A., J. Colloid Sci., 1963, vol. 18, p. 747.

136. Hansen, R.S. and Mann, S.A., J. Colloid Sci., 1963, vol. 18, p. 895.

137. Lucassen, J. and Hansen, R.S., J. Colloid Sci., 1966, vol. 22, p. 32.

138. Thiessen, D. and Schwartz, P., Z. Phys. Chem. (Leipzig), 1967, vol. 236, p. 363.

139. Lucassen, J. and Hansen, R.S., J. Colloid Sci., 1967, vol. 23, p. 319.

140. Platikanov, D., Panajotov, I., and Scheludko, A., Abh. Dtsch. Akad. Wiss. Berlin, Kl. Chem. Geol. Biol., 1966, vol. 66, p. 773.

141. Lucassen, J., Trans. Faraday Soc., 1968, vol. 64, p. 2221.

142. Lucassen, J., Trans. Faraday Soc., 1968, vol. 64, p. 2230.

143. Lucassen, J. and Van den Tempel, M., J. Colloid Interface Sci., 1972, vol. 41, p. 491.

144. Lucassen, J. and Barnes, G.F., J. Chem. Soc., Faraday Trans. 1, 1972, vol. 68, p. 2129.

145. Veer, F.A. and Van den Tempel, M., J. Colloid Interface Sci., 1973, vol. 42, p. 418.
146. Somasundaran, P., Danitz, M., and Mysels, K.J., J. Colloid Interface Sci., 1974, vol. 48, p. 410.

147. Garrett, P.R. and Joos, P., J. Chem. Soc., Faraday Trans. 1, 1976, vol. 72, p. 2174.

148. Lucassen, J., Hollway, F., and Buchingham, J.H., J. Colloid Interface Sci., 1978, vol. 67, p. 432.

149. Maru, H.C., Mohan, V., and Wasan, D.T., Chem. Eng. Sci., 1979, vol. 34, p. 1283.

150. Noskov, B.A. and Vasil'ev, A.A., Kolloidn. Zh., 1988, vol. 50, p. 909.

151. Noskov, B.A., Adv. Colloid Interface Sci., 1996, vol. 69, p. 63.

152. Noskov, B.A., Alexandrov, D.A., and Miller, R., J. Colloid Interface Sci., 1999, vol. 219, p. 250.

153. Sohl, C.H., Miyano, K., and Keterson, J.B., Rev. Sci. Instrum., 1978, vol. 49, p. 1464.

154. Pichard, C. and Davoust, L., Rheol. Acta, 2006, vol. 45, p. 497.

155. Bohanon, T.M., Mikrut, J.M., Abraham, B.M., et al., Rev. Sci. Instrum., 1991, vol. 62, p. 2959.

156. Howell, D.R., Buhrow, B., Heath, T., et al., Phys. Fluids, 2000, vol. 12, p. 322.

157. Behroozi, F., US Patent 6563 588, 2003.

158. Cinbis, C. and Khuri-Yakub, B.T., Rev. Sci. Instrum., 1992, vol. 63, p. 2048.

159. Stenvot, C. and Langevin, D., Langmuir, 1988, vol. 4, p. 1179.

160. Jayalakshmi, Y., Ozanne, I., and Langevin, D., J. Colloid Interface Sci., 1995, vol. 170, p. 358.

161. Noskov, D.A., Alexandrov, D.A., and Miller, R., J. Colloid Interface Sci., 1999, vol. 219, p. 259.

162. Safouane, M., Miller, R., and Möhwald, H., J. Colloid Interface Sci., 2005, vol. 292, p. 86.

163. Kapitsa, P.L., Zh. Eksp. Teor. Fiz., 1948, vol. 18, p. 3.

164. Schwarz, D.K. and Knobler, C.M., Phys. Rev. Lett., 1994, vol. 73, p. 2841.

165. Kurnaz, M.L. and Schwartz, D.K., Phys. Rev. E: Stat. Phys., Plasmas, Fluids, Relat. Interdiscip. Top., 1997, vol. 56, p. 3378.

166. Ivanova, A.T. and Schwarz, D.K., Langmuir, 2000, vol. 16, p. 9433.

167. Sacchetti, M., Tu, H., and Zografi, G., Rev. Sci. Instrum., 1993, vol. 64, p. 1941.

168. Stone, H.A., Phys. Fluids, 1995, vol. 7, p. 2931.

169. Mannheimer, R.J. and Schechter, R.S., J. Colloid Interface Sci., 1970, vol. 32, p. 195.

170. Wasan, D.T., Gupta, L., and Vora, M.K., AIChE J., 1971, vol. 17, p. 1287.

171. Nagarajan, R. and Wasan, D.T., Rev. Sci. Instrum., 1994, vol. 65, p. 2675.

172. Goodrich, F.C., Allen, L.H., and Poskanzer, A., J. Colloid Interface Sci., 1975, vol. 52, p. 201.

173. Derjaguin, B.V., Strakhovskii, G., and Malysheva, D., Zh. Eksp. Teor. Fiz., 1946, vol. 16, p. 171.

174. Derjaguin, B.V., Kusakov, M.M., and Krym, K.S., Zh. Eksp. Teor. Fiz., 1946, vol. 16, p. 179. 
175. Kusakov, M.M., Zh. Eksp. Teor. Fiz., 1946, vol. 16, p. 451.

176. Kusakov, M.M., Dokl. Akad. Nauk SSSR, 1946, vol. 54, p. 145.

177. Petkov, J.T., Danov, K.D., and Denkov, N.D., Langmuir, 1996, vol. 12, p. 2650.

178. Pierson, F.W. and Whitaker, St., J. Colloid Interface Sci., 1978, vol. 63, p. 129.

179. Lopez, J.M. and Hirsa, A.H., J. Colloid Interface Sci., 2000, vol. 229, p. 575.

180. Lopez, J.M., Miraghaie, R., and Hirsa, A.H., J. Colloid Interface Sci., 2002, vol. 248, p. 103.
181. Hirsa, A.H., Lopez, J.M., and Miraghaie, R., J. Fluid Mech., 2002, vol. 470, p. 135.

182. Constant, W.D., Wolcott, J.M., and Cambridge, V.J., US Patent 4884 437, 1988.

183. Chattopadhyay, A.K., Ghaicha, L., Oh, S.G., and Shah, D.O., J. Phys. Chem., 1992, vol. 96, p. 6509.

184. Hou, Y.Y. and Kassim, H.O., Rev. Sci. Instrum., 2005, vol. 76, p. 101101.

185. Patist, A., Chharra, V., Pagidipati, R., et al., Langmuir, 1997, vol. 13, p. 432.

186. Stevenson, P., J. Colloid Interface Sci., 2005, vol. 290, p. 603. 